\title{
Bluetooth as a traffic sensor for stream travel time estimation under Bogazici Bosporus conditions in Turkey
}

\author{
İker Erkan ${ }^{1} \cdot$ Hasan Hastemoglu ${ }^{1}$
}

Received: 21 January 2016/Revised: 28 March 2016/Accepted: 29 March 2016/Published online: 19 April 2016

(C) The Author(s) 2016. This article is published with open access at Springerlink.com

\begin{abstract}
Travel time estimation is an integral part of Intelligent Transportation Systems, and has been an important component in traffic management and operations for many years. Travel time, being spatial in nature, requires spatial sensors to measure it accurately. Bluetooth is emerging as a promising technology for the direct measurement of travel time, and is reported in a few studies from homogenous traffic conditions. At the same time, there have been no studies on the applicability of Bluetooth for travel time estimation in heterogeneous traffic seen in Istanbul and even that Turkey. Bluetooth data collected from a busy urban road in Istanbul city have been analyzed and the penetration rate was found to be about $5 \%$. Two wheelers and light motor vehicles have been detected using the Bluetooth sensor and the data have been extrapolated to estimate travel times of other classes of vehicles. The study developed linear relationships between speeds of different classes of vehicles through weighted linear regression methods and were used for the estimation of stream travel time. The results obtained were promising and show that Bluetooth is a cost-effective technology for estimation of travel time for heterogeneous traffic conditions.
\end{abstract}

Keywords Travel time $\cdot$ Public transport - Traffic management · Istanbul traffic · Traffic time estimation

İlker Erkan

ilkererkan@sdu.edu.tr

Hasan Hastemoglu

hasanhastemoglu@sdu.edu.tr

1 Faculty of Architecture, Suleyman Demirel University, 32260 Cunur, İsparta, Turkey

\section{Introduction}

The time taken to commute between two points in a traffic stream-the "travel time"-is useful information that can help the traveler plan their trip better. Travel time information is also an important parameter in Intelligent Transportation Systems, traffic demand modeling and prediction, traffic simulation, traffic signal timing control, incident detection, congestion management, and dynamic route assignment [1].

Travel time is a dynamic, spatial parameter that is difficult to measure directly for an entire travel stream. Sensors affixed at predetermined spots en-route a stream or within vehicles moving along the stream, can be used for direct travel time measurements. Automatic vehicle identification (AVI), License Plate Recognition Systems, Signature Matching Systems, Platoon Identification Systems, Global Positioning Systems (GPS), mobile phones, and Bluetooth are some common examples of devices that can be used as spatial sensors for travel stream analyses. Despite the apparent applicability of these sensors in measurement of travel time, many of them suffer from one or more of the following drawbacks: they provide no information on count, occupancy and flow, require user participation, have privacy issues and capture only a small fraction of the traffic $[2,3]$.

Bluetooth is increasingly being explored for travel time measurement applications. Preliminary studies in the West have proven cost-efficiency benefits of Bluetooth in spatial sensing in homogenous traffic conditions [4]. Agencies in the USA such as The Illinois Department of Transportation [5] and Houston Transtar already use Bluetooth sensors to collect travel time information.

However, there are no reports yet, on the use or study of Bluetooth sensors in the heterogeneous Istanbul Bosporus 
traffic scenario. The present study attempts to overcome this stalemate by evaluating the applicability of the Bluetooth sensor as a traffic data source under The Bogazici Bosporus traffic conditions.

Bluetooth can be used to measure travel times of those vehicles that have Bluetooth devices. This may only be a small fraction of all vehicles plying any particular route. Hence, it is important to understand the percentage of vehicles from which data can be collected using this method, namely penetration rate analysis. Also, it is important to know the class-wise distribution of vehicles from which data can be collected. This is particularly important for a country like Turkey, whose roads are characterized by heterogeneous traffic conditions-two (bicycles, motorbikes), three (auto rickshaws), and four wheelers (cars) share the road with light and heavy motor vehicles and a heavy pedestrian population.

This study performs penetration analysis and determines the class-wise distribution of Bluetooth-based data. A method for the estimation of stream travel time from the sampled data is also developed.

\section{Background and scope}

The state of the traffic is estimated using data from various sensors that range from traditional inductive loops to advanced Bluetooth MAC Scanners. Models have been proposed to estimate travel time (or speeds) [6, 7, 8-11] and density [12-14] from loop detector data.

Bluetooth uses low-power radio waves to wirelessly link various electronic devices over short distances (1-100 m). A Bluetooth device uses a 12-digit electronic identifier, called a Media Access Control address, or MAC address that serves as an electronic nickname for the device. An "inquiry" establishes continuous connection between MAC ID's. The anonymity of Mac ID's ensures privacy [5] and can be used as a handle to obtain traffic information.

In the present study, MAC ID's, which are captured by a Bluetooth sensor device, are replaced by an automatically generated random number, thus further obviating possible privacy intrusions. Travel time can be computed from Bluetooth sensor data by matching the IDs at two locations and calculating the difference between the arrival time stamps of the MAC ID at these locations.

Most existing studies on Bluetooth for traffic applications have focused on quality control of Bluetooth data and estimation of average speed or origin-destination $[4,5]$. In many of these studies, only a percentage of traffic streamthe sampling rate or penetration rate-is captured and used as the traffic data source. For example, a Bluetooth hourly sampling rate as low as $2 \%-4 \%$ was observed in a study at the University of Maryland [4]. In this study, it was found that the travel times obtained using Bluetooth sensors were comparable to those obtained using GPS. The study also proposed a two-step travel time filtering mechanism to estimate the upper and lower bounds from the distribution of travel time. The accuracy of measured travel time was reported to be better with increased distance between the two Bluetooth detectors and decreased vehicle speed.

Stevanovic and Martin [15] compared the travel times measured by Bluetooth MAC readers with that obtained using floating cars equipped with GPS. They reported that the travel times from the Bluetooth readers did not vary significantly (95\% level) from the GPS floating car travel time for $83 \%$ of the cases. Wang et al. [16] demonstrated that the travel time obtained from Bluetooth sensors with sampled data and that estimated from loop detectors are roughly similar.

An analysis of the impact of vehicle speed and effective range of the device on the number of in-range scan intervals for improvements in device detection was reported in [17].

Welsh et al. [18] worked on the improvements of the Bluetooth technology connection times between moving devices and proposed the creation of a mesh network of Bluetooth-connected devices. Ahmed et al. [19] further investigated the concept, envisioning the utilization of Bluetooth technology, in order to create a static mesh network for ITS data collection. The Bluetooth detection technology has been shown to be effective in several research studies $[19,20]$. Analyses for freeways and arterials demonstrated that methodologies based on data recorded by Bluetooth detectors are capable of capturing traffic conditions as accurately as other data sources, including intrusive methods, such as loop detectors as well as non-intrusive, such as Floating Car Data [4, 21-23].

Sadabadi et al. [24] estimated the upper bounds for the errors by using the relationship among the segment length, average speed, and travel time and showed that the travel time measurement error is negligible when the average speed is around $45 \mathrm{kmph}$ and the distance between two detectors is $2-3$ miles. Quayle et al. [21, 22] identified the upper and lower limits of travel times measured with a Bluetooth sensor, using a moving standard deviation [25].

Jaume et al. [26] studied the quality of the data produced by the Bluetooth and Wi-Fi detection of mobile devices to estimate time-dependent Origin-Destination matrices based on Kalman Filtering. Sawant et al. [27] used the concepts of wireless sensor networks and Bluetooth protocols to develop a novel approach that increased safety of road travel. Bullock et al. [28] studied the applicability of 
Bluetooth in measuring time spent waiting in security screening lines, transiting the security screening checkpoint, and walking to concourse in airports. A study by Blogg et al. [29] reported on the passive observations of Bluetooth protocol devices embedded in vehicles and motorists' mobile devices to collect the OD data.

$\mathrm{Li}$ et al. [30] compared the performance of various traffic data collection methods for urban road network environments, showing similarities, advantages, and disadvantages. This reference studied the quality of decomposed link travel times based on empirical data in the Chinese city of Changsha. They found that the accuracy typically is within a range of just $1 \mathrm{~s}$.

As with any travel time measurement method, sources of error exist and outlying data points must be addressed to ensure that accurate travel times are reported. Errors may appear in Bluetooth travel time measurements on arterials as a result of signal delay and non-uniform traffic flow [31]. The $10.24 \mathrm{~s}$ required to complete the Bluetooth inquiry process may introduce a major source of error and may result in inaccurate travel times, though this error decreases as the distance between Bluetooth stations increases [32, 33]. In recent years, applications of Bluetooth and cell phones have attracted many researchers in estimating travel time. Consequently, various studies have been presented in detecting and addressing outliers [31, 34]. Li et al. [35] examined traffic data gathered from taxicabs over 24 days by applying the Temporal Outlier Discovery (TOD) concept to detect temporal outliers. It has been widely reported that point-to-point data sources like the Bluetooth are self-sufficient, as far as the prediction of travel times is concerned [36-38]. However, the assumption that is often made is that the data samples are large enough for computing the statistics of interest [39].

On the other hand, in travel time estimation method, there are several data collected methods. In Liu et al. [40], the data collected by TRANSMIT readers, Bluetooth sensors, and INRIX were assessed by comparing each to the 'ground truth' travel times collected by probe vehicles carrying GPS-based navigation devices.

All studies reported above are from the Western traffic condition which is largely homogeneous in nature. While the basic principles of using Bluetooth for travel time prediction remain the same for heterogeneous traffic conditions, significant adaptations are required to suit the Turkey road. This study is a pioneer in the investigation of Bluetooth as traffic sensor under Turkey traffic conditions and presents penetration and class-wise distribution analyses, in addition to proposing a method to estimate stream travel time from sampled Bluetooth data.

\section{Data collection}

\subsection{Field data}

The Bogazici Bosporus is a gravity-anchored suspension bridge with steel towers and inclined hangers [41]. It is $1,560 \mathrm{~m}$ but the study stretch selected was the initial section of the Bosporus in Istanbul, Turkey. The two locations were selected (at a distance of $850 \mathrm{~m}$ ) (Fig. 1).

Bluetooth sensors were connected to laptops installed with 'Bluetooth View' software and placed at the two locations. When a vehicle fitted with a Bluetooth device crossed the sensor, the MAC ID and time stamp were automatically recorded by the software. Matching pairs were identified using data collected from the two locations. The difference between the arrival time stamps at the two locations for the corresponding matched MAC ID was considered as the travel time of the vehicle.

In all data collection activities, the traffic was simultaneously recorded on video in order to manually extract actual values of the total vehicle volume, classification, and travel time. Such information was useful for penetration analysis, class identification, and validation of estimated stream travel times.

Data were collected during two peak traffic periods (9.00-1.30 a.m. and 1.30-4.00 p.m.) for penetration analysis and also, someday, more data were collected (9.30 a.m.-9.30 p.m.) for class identification of vehicles.

\subsection{Simulated data}

The estimated stream travel time obtained from simulations studies was used for corroboration, because collection of data from field was strenuous and time-consuming. VISSIM was used to generate the data. Simulations were

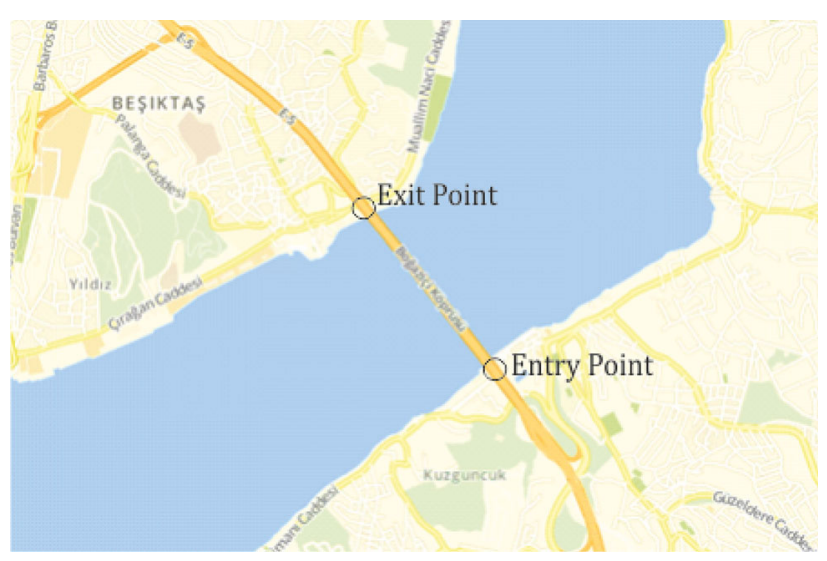

Fig. 1 Study site details 
performed using actual field flow information obtained on September 20th and 21st 2014 from an automated sensor. Travel time, classified speed, and flow data were generated for $24 \mathrm{~h}$ periods on both days and used to estimate stream travel time and develop and validate models.

\section{Results and discussion}

\subsection{Penetration rate analysis}

The percentage of the actual traffic captured by the Bluetooth sensor is generally called as the sampling rate or penetration rate [5] and is an important parameter to ascertain the adequacy of sample size for analysis. The penetration rate analysis was performed separately at entry and exit locations. From the raw data obtained using the Bluetooth sensor, the number of vehicles captured by Bluetooth at each location was obtained. The total number of vehicles passing each of these locations was obtained by manually counting the vehicles in the video. Such counts were made at 5-min intervals over the entire duration of data collection. The number of samples captured by Bluetooth divided by total vehicle flow during a particular 5-min period was taken as the penetration rate for that period. The maximum and minimum penetration rates at the two locations during the morning and evening hours are shown in Fig. 2.

It can be seen that the average penetration rate of Bluetooth was about $5 \%$. This value is comparable to the reported penetration rate in previous studies [4]. The sample size obtained is more than the GPS penetration rate in Turkey cities, which is available only from public transport vehicles. The Bluetooth sensor is thus a promising source for traffic data collection for Turkey conditions.

\subsection{Class identification of vehicles captured by Bluetooth sensor}

After knowing the penetration rate, it is important to understand the distribution of these Bluetooth devices among various classes of vehicles to ensure applicability of Bluetooth technology in accurate travel time estimation. Four major classes of vehicles were considered in this study:

- Two wheelers $(2 \mathrm{~W})$,

- Three wheelers (3W),

- Light motor vehicles (LMV), and

- Heavy motor vehicles (HMV).

To conduct this analysis, Bluetooth data and video data were collected simultaneously at the entry and exit locations. Matching pairs of MAC ID's and their corresponding

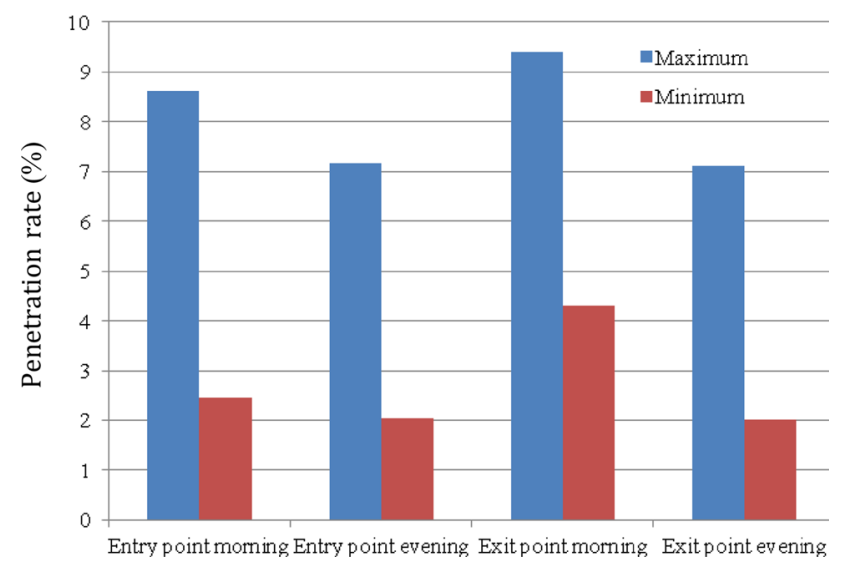

Fig. 2 Minimum and maximum penetration rates (\%)

arrival time stamps obtained from Bluetooth were first identified for the two locations. The arrival time stamp of a vehicle detected at the first location was matched with the time in the corresponding video to identify the possible class of the detected vehicle. This was repeated at the second location for the same Bluetooth ID and the common vehicle matching the time stamp in both the videos was identified as the vehicle corresponding to that Bluetooth ID. The videos at the two locations were visually compared in parallel for the corresponding arrival time stamps in order to identify the matching vehicle and class. The percent-wise distribution of different classes captured by the Bluetooth on a sample day is shown in Fig. 3. Similar observations were obtained on other days too.

It can be seen that more than $91 \%$ of vehicles captured using Bluetooth sensors were either LMV or $2 \mathrm{~W}$, indicating a possible bias of the Bluetooth to fast moving vehicles comprising mainly passenger cars and motorbikes. It is therefore necessary to project the data of these fast moving vehicles to the other two classes namely $3 \mathrm{~W}$ and HMV,

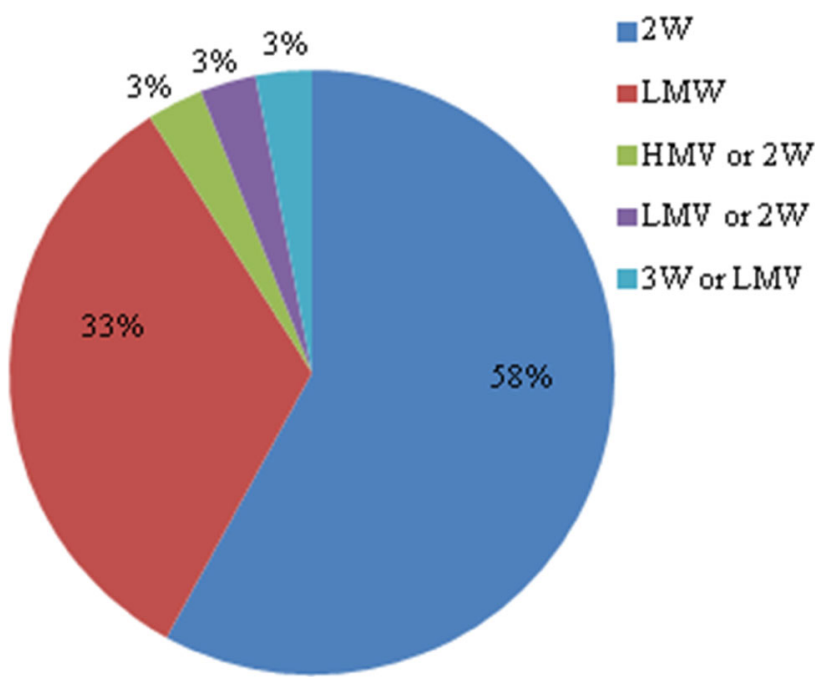

Fig. 3 Classes of vehicle identified by Bluetooth 
which move relatively slow, before using the data for stream travel time estimation described in the following section.

\subsection{Estimation of stream travel time}

It can be seen from penetration rate analysis and class identification studies that the Bluetooth has an average penetration rate of $5 \%$ in Turkey conditions, and captures mainly $2 \mathrm{~W}$ and LMV, which are grouped as High Speed Vehicles (HSV) in this study. The travel time captured by Bluetooth is thus the average travel time of HSV. The travel time of slow moving vehicles must be estimated from the measured travel time in order to compute the complete stream travel time.

The average speeds of HSV were calculated from the measured HSV average travel times using the known distance between the data collection points as

$V_{\mathrm{HSV}}=\frac{D_{12}}{T_{\text {Bluetooth }}}$,

where $T_{\text {Bluetooth }}$ is travel time measured by Bluetooth sensor, $V_{\mathrm{HSV}}$ speed of high speed vehicles and $D_{12}$ distance between the two detector stations.

The speed of the entire stream must be estimated from this speed of the HSV. The traffic composition in the study corridor was observed to be $45 \% 2 \mathrm{~W}, 6 \% 3 \mathrm{~W}, 47 \%$ LMV, and $2 \%$ HMV. Thus, a weighted average speed of the entire stream can be written as

$V_{\text {stream }}=0.45 V_{2 \mathrm{~W}}+0.06 V_{3 \mathrm{~W}}+0.02 V_{\mathrm{HMV}}+0.47 V_{\mathrm{LMV}}$,

where $V_{2 \mathrm{~W}}$ is speed of 2-wheelers, $V_{3 \mathrm{~W}}$ speed of 3 -wheelers, $V_{\mathrm{HMV}}$ speed of heavy motor vehicles, $V_{\mathrm{LMV}}$ speed of light motor vehicles and $V_{\text {stream }}$ average stream speed.

The corresponding stream travel time can be expressed as follows:

$T_{\text {stream }}=\frac{D_{12}}{V_{\text {stream }}}$,

where $T_{\text {stream }}$ is travel time of the stream.

To estimate the speed of slow moving $3 \mathrm{~W}$ and HMV from the travel time data of HSV, weighted linear regression was adopted. The speed of the $3 \mathrm{~W} / \mathrm{HMV}$ was taken as the dependent variable and the speed of the HSV as the independent variable as

$V_{3 \mathrm{~W}}=\alpha_{1} V_{\mathrm{HSV}}$

$V_{\mathrm{HMV}}=\alpha_{2} V_{\mathrm{HSV}}$

where $\alpha_{1}$ is coefficient obtained from regression between speed of $3 \mathrm{~W}$ and HSV; $\alpha_{2}$ coefficient obtained from regression between speed of HMV and HSV.
However, in linear regression, it is assumed that each data point provides precisely equal information, which may not always be the case. In such cases, to reduce error, weighted linear regression can be used, where each point is assigned a weight which regulates its influence in the estimation process. The scatter plot for the speed of $3 \mathrm{~W}$ and HSV is given in Fig. 4, where the scatter plot is funnel shaped indicating that the points have varying influence in the estimation process.

A similar shape was also observed in the case of HMV vs HSV. Hence, the weighted linear regression was used for establishing the relationship between the speeds of $3 \mathrm{~W}$ and HSV and speeds of HMV and HSV. Also, traffic conditions are dependent on the time of the day and there will be variations between peak periods and off-peak periods and nights. To identify these regimes, full day data obtained from VISSIM are plotted. A sample plot of travel time is given in Fig. 5. A travel time of $150 \mathrm{~s}$ was selected as a threshold between peak and off-peak flow regimes.

Based on this, the congested and normal flow regimes were identified and the relationship between the speeds of 3W and HMV with HSV were formulated separately for each of the flow regimes. The above scheme was implemented using simulated data in order to obtain sufficient

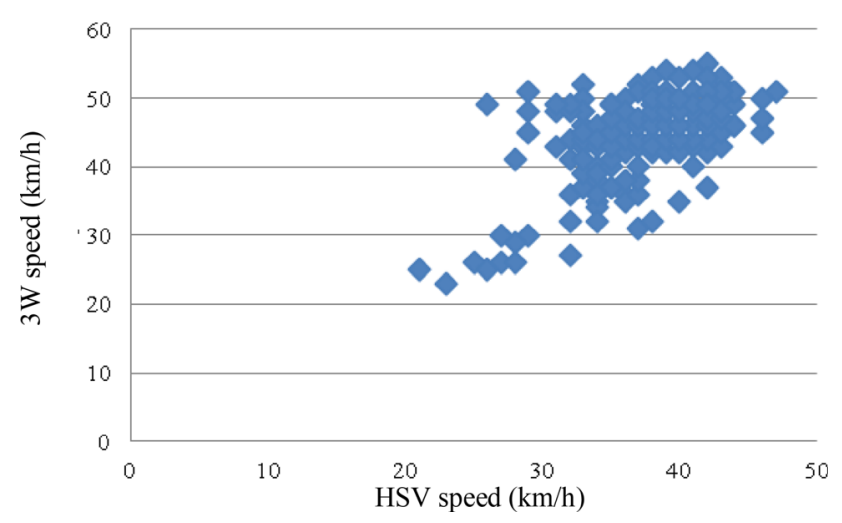

Fig. 4 Scatter plot of $3 \mathrm{~W}$ and HSV Speed

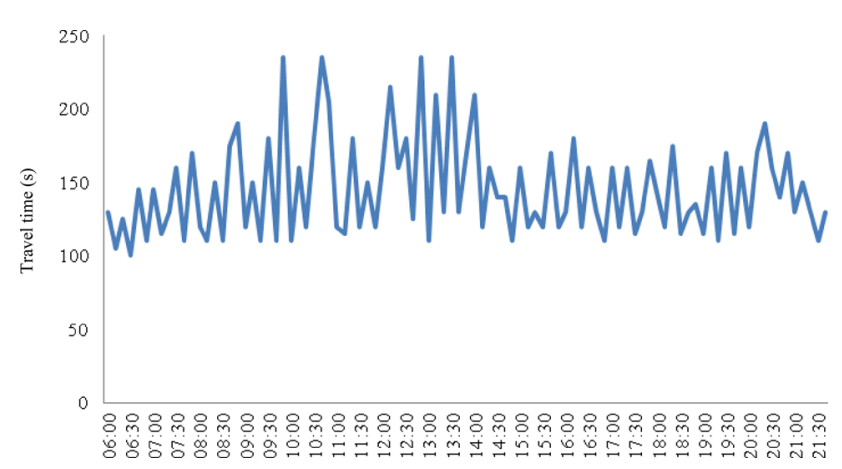

Fig. 5 Different flow regimes during the day 
sample size. The speed of HSV was assumed to be the average speed of LMV and $2 \mathrm{~W}$. The weights were assigned as the square inverse of the speeds and weighted linear regression was carried out using R-software.

An estimation of the linear relation between the speeds of different classes of vehicles was made from the linear regression. The average stream speed was estimated using Eq. (2) using the known speed of HSV and estimated speeds of $3 \mathrm{~W}$ and HMV. The different coefficients used to estimate average stream speed from speed of HSV for different times of the day are tabulated in Table 1. Tables 2 and 3 list the parameters obtained from the weighted linear regression for the 1:30-4:00 p.m. time period.

Validation was carried out using simulated data collected on a different day. Classified travel time and speed data were generated for the entire day and speed of HSV

Table 1 Coefficients for $3 \mathrm{~W}\left(\alpha_{1}\right)$ and $\operatorname{HMV}\left(\alpha_{2}\right)$ for different flow regimes

\begin{tabular}{llll}
\hline Class & 9:00 a.m.-1:30 p.m. & $1: 30-4: 00$ p.m. & 7:00-9:30 p.m. \\
\hline Linear coefficients & & \\
$\alpha_{1}$ & 0.84 & 0.783 & 0.81 \\
$\alpha_{2}$ & 0.83 & 0.793 & 0.83 \\
\hline
\end{tabular}

Table 2 R-output for linear regression for HMV

\begin{tabular}{lllll}
\hline Residuals & & & & \\
Min & 1Q & Median & $3 \mathrm{Q}$ & Max \\
-0.79380 & -0.07010 & 0.02565 & 0.08200 & 0.26518 \\
Coefficients & & & & \\
& Estimate & SE & $t$ value & $\operatorname{Pr}(>|t|)$ \\
HSV1 & 0.7938 & 0.0194 & 40.91 & $<2 \mathrm{e}-16^{* * *}$ \\
\hline
\end{tabular}

Residual standard error: 0.08983 on 144 degree of freedom (DF) (87 observations deleted due to missingness)

Multiple $R$-squared: 0.9871 , Adjusted $R$-squared: 0.987

$F$-statistic: $1.105 \mathrm{e}+04$ on 1 and $144 \mathrm{DF}, p$ value: $<2.2 \mathrm{e}-16$

Signif. codes: 0 ‘***, 0.001 ‘**’ 0.01 ‘*’ 0.05 ‘’ 0.1 ‘' 1

Table 3 R-output for linear regression for $3 \mathrm{~W}$

\begin{tabular}{lllll}
\hline Residuals & & & & \\
Min & $1 \mathrm{Q}$ & Median & $3 \mathrm{Q}$ & Max \\
-0.27594 & -0.05098 & 0.00462 & 0.04104 & 0.33671 \\
Coefficients & & & & \\
& Estimate & SE & $t$ value & $\operatorname{Pr}(>|t|)$ \\
HSV2 & 0.78406 & 0.00746 & 105.1 & $<2 \mathrm{e}-16^{* * *}$ \\
\hline
\end{tabular}

Residual standard error: 0.08983 on 144 DF

Multiple $R$-squared: 0.9871 , Adjusted $R$-squared: 0.987

$F$-statistic: $1.105 \mathrm{e}+04$ on 1 and $144 \mathrm{DF}, p$ value: $<2.2 \mathrm{e}-16$

Signif. codes: 0 '***' 0.001 '**' 0.01 '*’ 0.05 '? 0.1 ' ' 1 calculated as distance divided by travel time of HSV (average travel time of LMV and $2 \mathrm{~W}$ ). The speed of $3 \mathrm{~W}$ and HMV was estimated using the coefficients $\alpha_{1}$ and $\alpha_{2}$ obtained as above, and the total stream speed was calculated using Eq. (2). The estimated and actual stream speed for sample duration of 9:00 a.m.-1:30 p.m. are shown in Fig. 6.

The estimated speeds agree well with the actual speed values, as shown in Fig. 6. The corresponding stream travel time was calculated using Eq. (3) above and is shown in Fig. 7, along with the actual stream travel. Mean Absolute Percentage Error (MAPE), given by the following equation was used to quantify errors.

MAPE $=\frac{1}{n} \sum_{i=1}^{n}\left|\frac{T_{\mathrm{e}}-T_{\mathrm{o}}}{T_{\mathrm{o}}}\right| \times 100$,

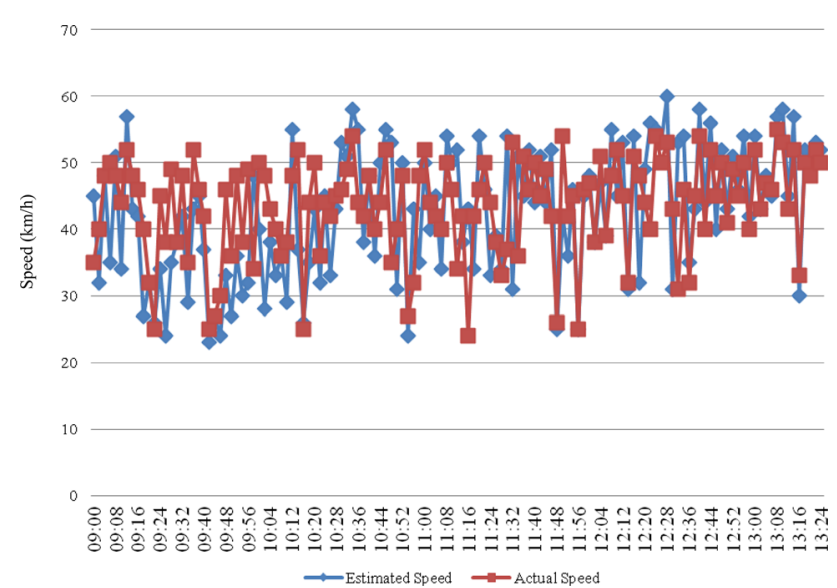

Fig. 6 Estimated and actual stream speed during 9:00 a.m.1:30 p.m.

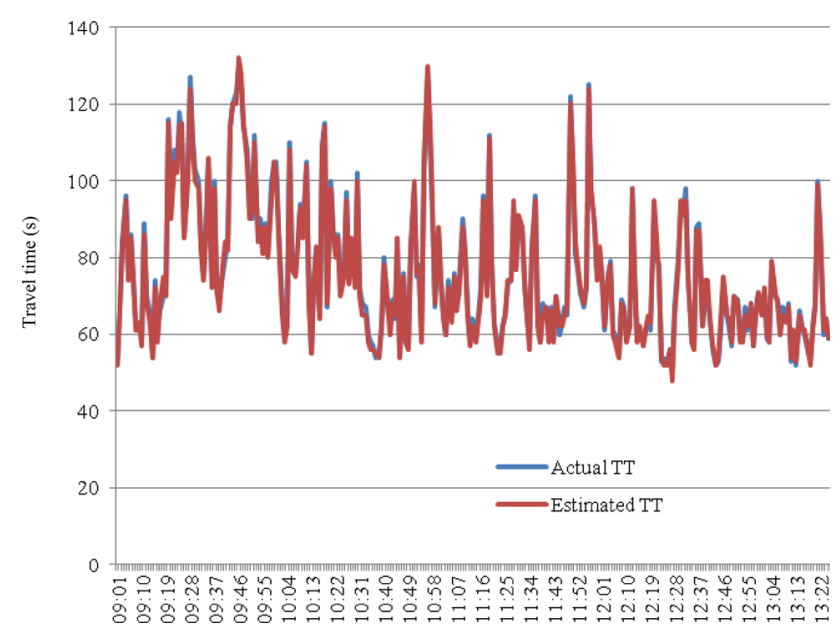

Fig. 7 Actual and estimated travel time for 9:00 a.m.-1:30 p.m. 


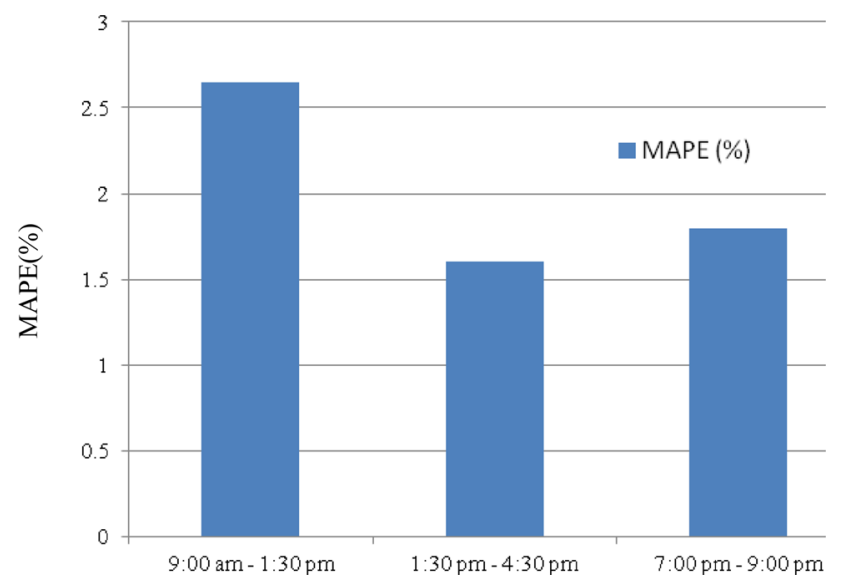

Fig. 8 MAPE values for different time zones

where $T_{\mathrm{e}}$ and $T_{\mathrm{o}}$ are the estimated and observed travel times.

Similar results were obtained for other time zones and the MAPE obtained for different time zones are shown in Fig. 8. It can be seen that the average error is around $2 \%$, indicating excellent performance of the scheme.

\section{Conclusions}

In this study, Bluetooth data collected from a busy road in Istanbul Bogazici Bosporus were analyzed for possible use as a traffic sensor. Penetration rate analysis, class identification, and estimation of stream travel time using Bluetooth have been demonstrated for the first time in Turkey. The penetration rate was found to be about $5 \%$. Majority of the detected vehicles were found to be two wheelers and light motor vehicles, indicating a bias in the data.

Estimating the stream travel time for an entire stream from limited Bluetooth data is a challenge and not many studies have addressed this problem until now. In this study, the data obtained from $2 \mathrm{~W}$ and LMV were extrapolated to estimate travel times of other classes of vehicles such as three wheelers and heavy motor vehicles to get a true estimate of stream travel time. The analysis was carried out separately for peak and off-peak traffic flow conditions. The study established linear relationships between speeds of different classes of vehicles through weighted linear regression analysis and estimated stream travel time as distance divided by stream speed. This technique was successful in estimating stream travel time accurately with an average MAPE of $2 \%$.

This study has shown that the Bluetooth is a cost-effective technology for estimation of travel time for heterogeneous traffic conditions. This study is the first of its kind to demonstrate the applicability of Bluetooth for travel time estimation under heterogeneous traffic conditions.

\section{Future study}

Much (more) transportation departments use inductive loops, traffic cameras, or stationary sensors to measure travel time for estimate travel time. Although these traditional systems are proven techniques of collecting traffic data, they each also have some shortcomings. Recently and alternatively, Floating Car Data method, Bluetooth, and GPS technologies have introduced an effortless method for traffic data collection and hereby traffic performance measurement. In the future study is going to try to investigate the use of GPS technology for stream travel time estimation under Turkey traffic conditions. In this case, some comparable or differences can be found between two technologies such as Bluetooth and GPS. After all, companies like Waze, TomTom, and Google are already able to provide city and country level traffic condition using GPS and other sources of data. For this reason, comparison is made among all technologies for travel time estimation under different conditions.

Open Access This article is distributed under the terms of the Creative Commons Attribution 4.0 International License (http:// creativecommons.org/licenses/by/4.0/), which permits unrestricted use, distribution, and reproduction in any medium, provided you give appropriate credit to the original author(s) and the source, provide a link to the Creative Commons license, and indicate if changes were made.

\section{References}

1. Lin HE, Zito R, Taylor MAP (2005) A review of travel time prediction in transport and logistics. Proc East Asia Soc Transp Stud 5:1433-1448

2. Soriguera Martí F, Rosas Díaz DM, Abeijón Monjas D, Thorson Bofarull L, Robusté Antón F (2007) Travel time estimation from multiple data sources. In: 11th world conference on transport research. University of California, Berkeley

3. Stiener A (2008) An improved method for travel time estimation on long freeway sections. In: conference paper STRC 2008, 8th Swiss transport research conference, Monte Verità, Ascona

4. Haghani A, Hamedi M, Sadabadi KF, Young S, Tarnoff P (2010) Data collection of freeway travel time ground truth with Bluetooth sensors, no. 2160, transportation research record, transportation research board of the national academies, Washington, D.C, pp 60-68

5. Young S (2008) Bluetooth traffic monitoring technology: concept of operation and deployment guidelines. University of MarylandCentre for Advanced Transportation Technology, Maryland

6. Coifman B, Kim S (2009) Speed estimation and length based vehicle classification from freeway single-loop detectors. Transp Res Part C Emerg Technol 17:349-364

7. Coifman B, Krishnamurthy S (2007) Vehicle reidentification and travel time measurement across freeway junctions using the 
existing detector infrastructure. Transp Res Part C Emerg Technol 15(3):135-153

8. Bhaskar A, Qu M, Nantes A, Miska M, Chung E (2015) Is bus overrepresented in Bluetooth MAC scanner data? Is MAC-ID really unique? Int J Intell Transp Syst Res 13(2):119-130

9. Cortes C, Lavanya R, Oh JS, Jayakrishnan R (2002) Generalpurpose methodology for estimating link travel time with multiple-point detection of traffic. Transp Res Rec J Transp Res Board 1802:181-189

10. Dailey DJ (1999) A statistical algorithm for estimating speed from single loop volume and occupancy measurements. Transp Res Part B Methodol 33(5):313-322

11. Wang Y, Nihan NL (2003) Can single-loop detectors do the work of dual-loop detectors? J Transp Eng 129(2):169-176

12. Qian QQ, Lin S, He ZY, Li XP (2012) Travelling wave timefrequency characteristic-based fault location method for transmission lines. Gener Transm Distrib IET 6(8):764-772

13. Sharma A, Bullock D, Bonneson J (2007) Input-output and hybrid techniques for real-time prediction of delay and maximum queue length at signalized intersections. Transp Res Rec J Transp Res Board 2035:69-80

14. Vigos G, Papageorgiou M, Wang Y (2008) Real-time estimation of vehicle-count within signalized links. Transp Res Part C Emerg Technol 16(1):18-35

15. Stevanovic AZ, Martin PT (2008) Assessment of the suitability of microsimulation as a tool for the evaluation of macroscopically optimized traffic signal timings. J Transp Eng 134(2):59-67

16. Wang Y, Malinovskiy Y, Lee UK, Wu YJ (2011) Investigation of bluetooth-based travel time estimation error on a short corridor. In: Transportation research board 90th annual meeting (No. 11-3056)

17. Bakula C, Schneider IV WH, Roth J (2011) Probabilistic model based on the effective range and vehicle speed to determine Bluetooth MAC address matches from roadside traffic monitoring. J Transp Eng 138(1):43-49

18. Welsh E, Murphy P, Frantz JP (2002) Improving connection times for Bluetooth devices in mobile environment. In: Proceedings of the 2002 international conference, on fundamentals of electronics communications and computer science of IEICE (ICFS 2002), 27-28 Mar 2002, Tokyo, Japan, pp 1-5

19. Ahmed H, El-Darieby M, Abdulhai B, Morgan Y (2008) Bluetooth- and Wi-Fi-based mesh network platform for traffic monitoring. In: TRB 87th annual meeting compendium of papers DVD, 13-17 Jan 2008, Washington, DC, pp 1-11

20. Sharifi E, Hamedi M, Haghani A, Sadrsadat H (2011) Analysis of vehicle detection rate for Bluetooth traffic sensors: a case study in Maryland and Delaware. In: Proceedings of the 18th world congress on intelligent transport systems, 16-20 Oct 2011, Orlando, FL, pp 1-12

21. Quayle SM, Koonce P, DePencier D, Bullock DM (2010) Arterial performance measures with media access control readers: Portland, Oregon, pilot study. Transp Res Rec J Transp Res Board 2192:185-193. doi:10.3141/2192-18

22. Quayle SM, Koonce P, DePencier D, Bullock D (2010) Arterial performance measures using MAC readers: Portland pilot study. In: Transportation research board annual meeting proceedings CD-ROM

23. Wasson JS, Sturdevant JR, Bullock DM (2008) Real-time travel time estimates using media access control address matching. ITE J 78(6):20-23
24. Sadabadi KG, Hamedi M, Haghani A (2010) Evaluating moving average techniques in short-term travel time prediction using an AVI dataset. In: Transportation research board, annual meeting proceedings CD-ROM

25. Huston TranStar and Bluetooth Traffic Monitoring (2012). http://traffic.houstontranstar.org/bluetooth/transtar_bluetooth.html. Accessed 22 July 2013

26. Jaume B, Lídia M, Laura M, Carlos C(2010) A Kalman-filter approach for dynamic OD estimation in corridors based on Bluetooth and WiFi data collection. 12th WCTR, Lisbon, Portugal

27. Sawant H, Tan J, Yang Q, Wang Q (2004) Using Bluetooth and sensor networks for intelligent transportation systems. In: IEEE intelligent transportation systems conference, Washington, D.C., USA

28. Bullock D, Haseman R, Wasson J, Spitler R (2010) Automated measurement of wait times at airport security: deployment at Indianapolis international airport, Indiana. Transp Res Rec J Transp Res Board 2177:60-68

29. Blogg M, Semler C, Hingorani M, Troutbeck R (2010) Travel time and origin-destination data collection using Bluetooth MAC address readers. In: Australasian transport research forum, pp $1-15$

30. Li J, Van Zuylen H, Liu C, Lu S (2011) Monitoring travel times in an urban network using video, GPS and Bluetooth. Procedia Soc Behav Sci 20:630-637. doi:10.1016/j.sbspro.2011.08.070

31. Van Boxel D, Schneider W IV, Bakula C (2011) Innovative realtime methodology for detecting travel time outliers on interstate highways and urban arterials. Transp Res Rec J Transp Res Board 2256:60-67

32. Malinovskiy Y, Lee UK, Wu YJ, Wang Y (2011) Investigation of Bluetooth-based travel time estimation error on a short corridor. In: Transportation research board 90th annual meeting (No. 11-3056)

33. Puckett DD, Vickich MJ (2010) Bluetooth ${ }^{\circledR}$-based travel time/ speed measuring systems development (No. UTCM 09-00-17)

34. Horn C, Klampfl S, Cik M, Reiter T (2014) Detecting outliers in cell phone data: correcting trajectories to improve traffic modeling. Transp Res Rec J Transp Res Board 2405:49-56

35. Li X, Li Z, Han J, Lee JG (2009) Temporal outlier detection in vehicle traffic data. In: IEEE 25th international conference on data engineering, 2009. ICDE'09, IEEE, pp 1319-1322

36. Khoei AM, Bhaskar A, Chung E (2013) Travel time prediction on signalised urban arterials by applying SARIMA modelling on Bluetooth data. In: 36th Australasian Transport Research Forum (ATRF) 2013

37. Khosravi A, Mazloumi E, Nahavandi S, Creighton D, Van Lint JWC (2011) A genetic algorithm-based method for improving quality of travel time prediction intervals. Transp Res Part C Emerg Technol 19(6):1364-1376

38. Qiao W, Haghani A, Hamedi M (2013) A nonparametric model for short-term travel time prediction using bluetooth data. J Intell Transp Syst 17(2):165-175

39. Nantes A, Ngoduy D, Miska M, Chung E (2015) Probabilistic travel time progression and its application to automatic vehicle identification data. Transp Res Part B Methodol 81:131-145

40. Liu X, Chien S, Kim K (2012) Evaluation of floating car technologies for travel time estimation. J Mod Transp 20(1):49-56

41. GDH (2014) General directorate of highways in Turkey: project information about the Bosphorus bridge report 